\title{
for(e)dialogue
}

Department of Media and Communication

Volume 1, Issue 1: New Directions in Media Research 2015

Public Service Broadcasting: the challenge of representing ethnic minority audiences

Gurvinder Aujla-Sidhu

(p. 40-51)

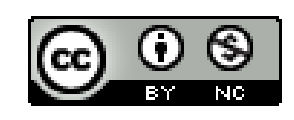

This work is licensed under a

Creative Commons Attribution- Non Commercial 4.0 International License

March 2016 


\section{Public Service Broadcasting: the challenge of representing ethnic minority audiences}

\section{Gurvinder Aujla-Sidhu}

Abstract: This paper examines the problems the $B B C$ has in engaging and representing minority audiences. The Director General of the BBC, Tony Hall, has claimed that he wants the future $B B C$ to "represent every family and community in the UK" (June 2014). Not an easy feat when the BBC's own research indicates that it is failing to attract ethnic minority audiences (BBC Service Review 2012). Critics such as Hall (1990) have suggested the problem is the media construction of "race" as an issue and its definitions. The paper will focus on the BBC Asian Network, a radio station which was almost closed down in 2010, ostensibly because it was the most expensive BBC radio service to operate, and had very low listener figures. Producers and Editors explain the issues they face in attracting and retaining the target audience.

Keywords: Ethnic Minorities, representation and Public Service Broadcasting, BBC, Asian, BBC Asian Network

\section{Introduction}

Since the 2010 General Election the BBC has undergone a period of sustained scrutiny by the Government and from commercial media particularly in the aftermath of the Jimmy Saville scandal. In 2009 the BBC agreed to a licence freeze, which led to a series of high profile cuts, called Delivering Quality First, a plan that proposed the closure of two of its digital radio stations. In 2015 the BBC agreed with the Conservative Government to fund licence fees for the over 75's, at a cost of around 750 million British Pounds, in return for an increase in line with inflation to the licence fee. Critics claim the move will mean a twenty per cent cut in funding, which may lead to further job cuts and further cuts to some BBC Services. The BBC Charter Review consultation report (2015) examines how the BBC should be funded in the future and questions the core BBC mission of serving 'all audiences' asking if it should instead focus on underserved audiences. The white paper will be published in 2016 and is expected to have a huge impact upon the future direction, size and funding of the BBC.

The charter renewal consultation draws attention to the fact that the BBC continues to struggle to reach black, Asian and minority ethnic audiences despite offering a dedicated radio service, the BBC Asian Network that produces content specifically for approximately four million people in the UK who describe themselves of South Asian descent. The BBC Asian Network was created when the 
Volume 1, Issue 1: New Directions in Media Research 2015

BBC bought together a number of regional radio programmes for Asian communities and united them, under the new remit covering news, music and events from UK Asian communities and South Asia diaspora (including India, Pakistan, Sri Lanka and Bangladesh). It broadcasts in English on DAB, with a limited number of hours delivered in a range of South Asian languages. The target audience for the station is British Asians aged up to thirty-five years of age, a group that the BBC described as "under-served" (DCMS 2004, p.26). But within a decade of the station's launch, the BBC proposed its closure, as part of Delivering Quality First (DQF) in 2009, because they claimed that low listener figures made the Asian Network the most expensive BBC service to run. The BBC suggested that the money saved could be reinvested in delivering content to Asian audiences within its wider portfolio of television and radio even though $\mathrm{BBC}$ generic research revealed that the $\mathrm{BBC}$ failed to attract black, Asian and other minority ethnic groups (BAME) to its news and radio output (BBC Service Review, 2012, p.13). After a public consultation, the plans were rejected by the BBC Executive in 2011 and it proposed the Asian Network should continue to exist but on a significantly reduced budget.

This paper examines the challenges the BBC Asian Network faces in trying to represent all Asian communities under a single service, which broadcasts mostly in English. By using academic literature about ethnic minority representation and material from five interviews with members of current and former BBC Asian Network staff in 2014 and 2015, this paper tries to demonstrate the difficulties that specialist services have in reaching minority audiences. The face to face interviews are a sample from an on-going project. Within the sample presented in this paper, is a former news editor, a current news editor, a former local radio manager, a former planning editor and a senior member of staff. Open-ended questions, tailored to each interviewee's specific role, were posed as well some generic questions to all interviewees. Thematic analysis was used to analyse the responses by classifying the transcripts and examining what themes and trends emerge. What is revealed from the interview data presented in this paper is that the journalists working for the Asian Network believe it is a valuable service, but they feel the $B B C$ in its entirety needs to do more when representing ethnic minorities. The BBC Asian Network cannot alone attract, engage and represent all South Asian people for the BBC. This paper also explores the future of the service, and questions if the BBC Asian Network will be required for subsequent generations of British Asians. Already second, third and other generations of British born Asian's are served by a range of other BBC radio stations for news and sport and commercial radio stations offer Bollywood music.

All media outlets are under pressure to improve their representation of minority groups and to recruit more ethnic minority journalists. As a result, in June 2014 the BBC announced a new diversity 
Volume 1, Issue 1: New Directions in Media Research 2015

strategy, which included a 2.1 million pounds' fund to help Black, Asian and minority ethnic (BAME) talent on and off screen, and to help BAME staff to move into senior management roles. But critics have suggested the money should be ring fenced specifically for some programmes or that the BBC should spend more money (Albury, 2015). BBC Director General, Tony Hall has said he wants the BBC to "represent every family and community in the UK" (BBC Media Centre, 2014). Limited progress has been made, the proportion of staff describing their background as a minority stood at 13.2 percent in February 2015 compared to 12.6 per cent in March 2014 (BBC Annual Report and Accounts 2014-15, p.88). The problem, however, is not recruiting ethnic minority staff but retaining them; in 2013-14 more ethnic minority staff resigned than were recruited (Burrell, 2014). This could be because most ethnic minority staff are concentrated in the lower page grades or they hit a ceiling where progression to senior levels does not take place.

\section{The BBC and Ethnic Minority Representation}

The BBC is mandated by law to produce programmes, "that reflect the lives and concerns of different communities and cultural interests and traditions within the United Kingdom" (Communications Act, 2003, s. 5. p.236). For decades the BBC has been criticised for failing to represent ethnic minority communities on and off screen. Cottle $(2000, p .102)$ has suggested that "ethnic minority programmes all too often fail to give robust representations to the diversity and difficulties of minority communities, cultures and identities." Campion (2005, p.4) has argued that broadcasters have misinterpreted cultural diversity to only mean more Black and Asian faces on screen, rather than programme content reflecting specific cultures and identities. Critics of public service broadcasting condemn BBC expansion, and the licence fee, because they suggest the BBC is given a "public policy directive" to build an empire giving it an "unfair advantage" (Brooks, 2006). There has also been a move from commercial media to have the licence fee 'top sliced' for other broadcasters. The Department of Culture, Media and Sport in a 2006 report described the issue as a "conundrum" and suggested that the BBC has to be a "strong broadcaster with universal reach" but one that does not stifle "innovation elsewhere" or uses its "unique advantages unfairly to compete with others" (DCMS, 2006 p.2).

Unlike other public service broadcasters, Kumar (1977, p.234) suggests the BBC is "unique" because some people consider the organisation to be part of the "national culture." The BBC is mandated to promote a "sense of national identity" (Communications Act, 2003). But this causes problems for the BBC when the idea of identity or Britishness itself becomes complicated. Changes to immigration laws have meant that politicians often emphasise a need for minorities (particularly Muslims) to integrate into the British way of life. Malik argues that, as a result broadcasters have 
Volume 1, Issue 1: New Directions in Media Research 2015

turned away from celebrating multiculturalism within programmes and instead focus on a "perceived need for social cohesion" (2013, p.228). Subsequently, news and current affairs outputs often frame stories as 'us' and 'them,' where the immigrants become the 'other'.

\section{Academic research}

Two key themes emerge from academic research about ethnic minorities and the media; that ethnic minorities on TV, are frequently portrayed in stereotypical ways for example: "terrorism, violence, conflict, and carnival" (Campion, 2005, p.24) or they usually appear within negative stereotypes in the news stories (Hartmann \& Husband, 1974; Cohen \& Gardener, 1982). Secondly the language used within stories about ethnic minorities in the news is often considered to be 'racist' (Van Dijk, 1998; Barker, 1981; Hall, 1990) by the minority communities. On screen, particularly in terms of newsreaders and reporters, the numbers from minority groups has increased. Malik (2008) suggests the emphasis on "Asianness" is fuelled by the "positive co modification of a globalised, Bollywood influenced South Asian popular culture and the negative preoccupation with Islam" (Malik, 2008, p.352). Members of the Muslim community believe they are represented in a "distorted and stereotypical" manner and the more they practice their faith the more their "seemingly alien culture" is perceived as a threat (Abbas, 2001, p.251).

Saha $(2012$, p.427) has argued that there is a tension between "public service ideals (ideas about citizenship, national identity and cultural diversity) and market forces." He believes that because the BBC and Channel 4 have struggled with limited finances they have focused on programmes with appealing broad formats rather than offering programmes geared specifically towards minority audiences and that the almost closure of the BBC Asian Network is indicative of this $(2012$, p.227).

The manner in which PSBs in the UK manages issues of race and racism may influence how the public in general perceive them. One key problem is that there is no single tangible, definitively limited thing called racism (Fenton, 2003, p.131). Instead there are a number of contexts or situations "in which 'others' are represented as inherently different or lesser and these representations become defining elements of the relationship." Hall $(1990$, p.9) has argued that 'racism' is one of the most profoundly "naturalised" ideologies because the media is able to create a definition of what race is to help audiences "make sense of the social world" but, at the same time it also defines what the "problem of race" is understood to be' (1990, p.11). 
Volume 1, Issue 1: New Directions in Media Research 2015

Saha (2012) has demonstrated that Asian producers are complicit in the process of "problematic representations of race" (2012, P.436). His interviews with ethnic minority television producers revealed they presented ideas for commissioning, based only on what would draw in large audiences. Saha argues that this illustrates a "different kind of institutional racism," where:

rationalized, standardized and commercially driven processes of contemporary television production are inscribed with a broader neocolonial logic that coaxes black and Asian cultural producers into creating reductive representations of difference. $(2012$, p.436)

\section{BBC Asian Network and Its Objectives}

The BBC Asian Network is the only BBC radio service specifically targeting South Asian audiences with a mix of music such as Bollywood and Bhangra, and news about the communities. This part of the paper will demonstrate how the BBC Asian Network is combating under representation and misrepresentation by allowing voices that are not usually heard on mainstream media on-air, thus making the service very useful, within the BBC's portfolio. The 2011 census revealed that three million people in the UK described themselves as being of Indian, Pakistani or Bangladeshi heritage and, unlike some minority communities, these groups retain very close ties to their homelands, culture, religion and languages.

The unique target audience and their different needs could go some way to explain some of the problems the BBC Asian Network has faced such as lack of engagement from the intended target audience and its proposed closure as part of the BBC's Delivering Quality First (DQF) policy. The key focus of the DQF was to cut spending by twenty percent but to still deliver the highest quality programmes. The problem posed by the closure of the BBC Asian Network was that the BBC still needed to offer something for minority audiences because, at least in theory, audiences lie at the "heart" of the organisation according to the BBC webpage outlining its missions and values. (BBC, Missions and Values,).

An independent review of digital radio, carried out in 2004 by the Department for Culture, Media and Sport, was critical of the station and called for the remit to be strengthened in order to attract a core target audience, because at that time the station was trying to be "all things to all Asians" (DCMS, 2004, P.50). The review also pointed out that the continued growth and fragmentation of the Asian community would "increasingly question the notion of a homogenous Asian community with a body of shared values and interests" in the future (p.50). 
Volume 1, Issue 1: New Directions in Media Research 2015

\section{Asian Network Analysis with interview data}

The term 'Asian' itself has always posed problems for the British media and academics alike because it implies a homogenous and united group with no recognition of their conflicting and disparate beliefs. However, among the Asian communities there is conflict and also consensus. The communities identify themselves mostly via religion or language. Husband $(1994, p .11)$ labels the term Asian as "functionally meaningless", because it imposes a specific identity onto people. In addition, he suggests that groups are "radically fractured by age, gender, class and political affiliation", but for commercial purposes minority ethnic media serve a broad diverse audience (2005, p.463).

Four out of the five interviewees believe the BBC overall lacks knowledge about the various Asian communities. Mike Curtis, a former news editor and Network Manager at the Asian Network, described the complexities of representing these communities:

It (the $B B C$ ) said here is something for the Asians across the UK go and sort it. It was down to us on the ground, the journalists and presenters to pick away through that, to be fair and balanced to all groups. People outside the Asian Network within the BBC didn't really understand how diverse those communities were. We produced documentaries about racism within the Asian communities; we had interviews with Asian people complaining about immigration. Which certain people in the BBC didn't understand that, they saw the word Asian, the one stop shop for everybody and that was it. (Curtis, 2013)

The lack of understanding historically, often meant some of the content produced was not pushed to other parts of the BBC. The Asian Network of 2015 has a more central role within the BBC, and is increasingly seen as the centre for specialist knowledge for Asian communities. However, the question of how to represent one group or a number of them is something that current News Editor Kevin Silverton, says is something the entire station grapples with:

The question is sometimes do you have to appeal to all of them or can you be more specific? And how often can you do that? So how alienating is it to a Muslim audience if you just talk to talk about Sikh issues for instance? Or are there enough commonalities across the Asian population that you are interested in a kind of shared experience because that is the experience of being from a specific background and culture within Britain? (Silverton, 2015) 
Volume 1, Issue 1: New Directions in Media Research 2015

News is unpredictable and some issues dominate the agenda for weeks and months which can mean one community getting prolonged coverage over the others. However, what singles Asian Network news from the rest of the $B B C$ is that the news involves members of the various Asian communities. Frequently news provided by mainstream broadcasters gives the "definition of the situation" (Cottle, 2000, p.37), which is often provided by those in a position of authority or "white elites" (Van Dijk, 1993, p.22). Van Dijk's research (1998) has identified that people from ethnic minority groups are quoted "less and less prominently than (white) elites" particularly within the press" Van Dijk (1998), as cited in Cottle (1998, p .39). Asian Network reporters interview ordinary Asian people on stories and by doing this Asian Network journalists challenge academic research findings that suggest all news output is similar, because journalistic conventions, routines and tight deadlines lead to the "over-accessing" of those "in powerful and privileged institutional positions" (Hall et al. 2013, P.61).

The BBC Asian Network output does have its limitations; most non-Asians perhaps do not consider listening to it and the few news stories that are shared across the BBC for Breakfast, News24, Radio 4 or 5 Live, tend to have a broad appeal. The crux of the problem is that the media, particularly the manner in which mainstream media frames a story, is how the general public form their opinions on issues such as immigration. The media are therefore a "powerful source of ideas about race" (Hall, 1990, p.11-12). But one senior member of staff believes the lack of ethnic minority representation elsewhere in the $\mathrm{BBC}$ is the result of $\mathrm{BBC}$ working practices.

I think in the BBC we have a particular way of working and I think we are formulaic sometimes especially when it comes to dealing with diverse communities. I mean if we look at the big issues that are always picked up by either the Asian Network or 5 Live or the BBC, it tends to be with things like radicalisation, forced marriages those are important issues, very important issues and we should be talking about them. (Anon, 2015)

Original stories about the Asian communities are shared within the BBC, for example on Breakfast, online or Newsnight. But this senior staff member is frustrated by the type of stories selected by the wider BBC.

The moment I mentioned the word Muslim, or radicalisation or forced marriage they (the BBC) loved the story. No matter how many times it was done. That for me was a frustration (Anon, 2015)

This supports Malik's (2001) suggestion that the media focus on Islam in their output. Some community groups, particularly Muslims, do not always trust BBC output, because of the framing, language or stereotypes used within the news (Harb and Bessasio, 2006, P.41). One of the first jobs 
Volume 1, Issue 1: New Directions in Media Research 2015

the first News Editor for the Asian Network, Mike Curtis dealt with was the creation of a unique style guide for the producers. The journalists at the Asian Network believed at that time that mainstream BBC used language and phrasing which was insensitive to the Asian Network's target audience, obvious examples including 'Islamic terrorists or militants'. Mike Curtis explained why this was essential to connect to the audience and gain their trust:

It was important that we phrased things correctly, even saying communities plural than community for talking about Asian communities. (Curtis, 2014)

The Asian Network has always attempted to reach all Asians but the station has not always succeeded. In 2009 Sikh organisations accused the BBC of being insensitive to their religion, after a Muslim Asian Network presenter suggested on air that Sikh's did not need to wear their ceremonial dagger at all times. Lord Indarjit Singh, from the Network of Sikh Organisations suggested in an interview for a news article "that stations like the Asian Network do little to encourage integration and social cohesion because they allow communities to ghettoise themselves" (Times of India, 2009). But Asian Network journalists believe the service reflects and gives insight into the British Asian lifestyle. Audience figures for the station have been increased, to 562,000 in 2014 (Quarter 1, 2014) following a high of 668,000 in (Quarter 4, 2013). But compared to the potential size of the target audience it is evident that many British Asians are not tuning in. Kamlesh Purhoit is a former Planning Editor for the Asian Network:

Unfortunately, in the BBC what is happening is that there are people with pre-formed ideas and pre-conceived kind of thoughts about what are the important stories for their output. Then the BBC cannot complain that not enough Asian people watch the BBC output or listen to $\mathrm{BBC}$ radio. Its then no surprise if most of the Asian families I know will watch Zee TV or Sony TV and watch all the soaps and the dramas and DTV for their news when actually they should be as licence fee payers be getting those services from the BBC. (Purhoit, 2015)

A BBC Trust review of music stations in 2015 revealed that only thirty-four percent of black, Asian and minority ethnic adults listen to at least one of the BBC's music stations a week. (BBC Trust, 2015, p13), compared to forty-nine percent of listeners from non-ethnic backgrounds. Kamlesh Puroit outlined the difficulties the station faces in targeting its audience.

I think in many ways it's become even more complicated more difficult. That may sound like an irony, because the Asian Network is much more focused now towards a younger audience. Those people more or less are people born in this country or came here at a very 
Volume 1, Issue 1: New Directions in Media Research 2015

young age and are very much integrated into British life I am not sure they need an Asian Network. (Purhoit, 2015)

It is often suggested that British Asians are served by the BBC's other radio stations, but the figures from the BBC Trust review above clearly contradict this point.

Owen Bentley, is the former Local BBC Radio network manager, and was involved in establishing the BBC Asian Network, he believes the problem with poor representation is not just top down, but also to do with audience experiences which are not always given a robust representation or understanding in output. An example is the Asian Network's short lived soap, Silver Street, which was axed a couple years after it was launched. Bentley suggests it was because it was a BBC Executive idea rather than the BBC Asian Network.

It never took off, that's a lot to do with listening habits if you never been used to a soap opera you don't then get into it on radio. But one thing I notice as an outsider to the Asian community, was that the people they had recruited all Asian, were not basically in touch with the working class of the Asian community at all; they were all graduates they were all very much of the London literary scene, and so I though the drama never really ever managed to get down to an average Asian family in Birmingham or Leeds or whatever. (Bentley,2015)

This is a wider criticism directed at the BBC that its programmes do not represent the working classes and the staff make-up also fails to do so. An essential requirement for most entry level jobs at the $\mathrm{BBC}$ is a degree and this frequently excludes poorer sections of the audiences, and to an extent some ethnic minority groups. Despite the difficulties the Asian Network has faced, a senior member of staff described the station's goals and the output as "incredible:"

As public service broadcasters it is a really important job to reflect those 4.8 million people and to represent them fairly and to a broader audience. What the Asian Network's role in that is perhaps a vehicle to bring people into the $\mathrm{BBC}$ and to then push them around show them what else they might like. (Anon, 2015)

\section{Conclusion}

This paper has demonstrated why the BBC has to represent ethnic minority audiences. However, to attract viewers or listeners, programmes are frequently tailored for a broad mainstream appeal to the detriment of minority groups. To summarise, producers at the station believe they inform, 
Volume 1, Issue 1: New Directions in Media Research 2015

educate and entertain British South Asian communities. But they feel the BBC needs to give a more accurate representation of the British Asian communities on screen.

The gap between the licence fee payer and the BBC will continue to widen unless the BBC begins to develop more programmes that appeal to minorities, and the working classes, the two groups the BBC Asian Network does serve. The notion of public service broadcasting that reflects all communities could become redundant following the Charter Review Consultation. Also a move to a subscription form of funding instead of a licence fee in the future could also mean there may be no need for the BBC Asian Network or for BBC television to showcase Asian actors.

What this paper has also tried to suggest, is that the BBC Asian Network, cannot alone engage and represent people from South Asian backgrounds, more needs to be done across the entire BBC. The modest success of the BBC comedy Citizen Khan, attracting around 2.7 million viewers, reveals that audiences will consume programmes written and cast with ethnic minority actors. In fact the need for television to screen relevant programmes to these audiences has never been greater, but optimistically hoping that a digital radio service can be 'all things to all Asians' does not appear to be working for the BBC in serving this broad but diverse group.

\section{References}

Abbas, T. (2001) 'Media Capital and the Representation of Muslims in the British Press an Ideological Analysis', Journal of Muslim Minority Affairs, 21(2), pp. 245-257.

Anonymous, (2015) face to face Interview with author, 17 March

Albury, S. (2015) 'The BBC can't show it's serious about diversity without putting up the cash', The Guardian, 3 July.

Barker, M. (1981) The New Racism: Conservatives and the ideology of the tribe. London: Junction books.

BBC Media Centre, (2014)' Tony Hall unveils action plan to tackle on and off-air BAME representation at $B B C^{\prime} .14$ June. Available at http://www.bbc.co.uk/mediacentre/latestnews/2014/bamerepresentation-plans (Accessed: 4 Jan 2016)

BBC Trust. (2015) Service Review, Radio 1, 1Xtra, Radio 2, Radio 3, 6 Music and Asian Network

BBC Trust. (2012) Service Review, BBC Asian Network. http://downloads.bbc.co.uk/bbctrust/assets/files/pdf/our work/asian network/asian network.p df (Accessed: 30th April 2015)

BBC Trust Mission and Values, Available at http://www.bbc.co.uk/corporate2/insidethebbc/whoweare/mission and values (Accessed: 10 May 2015) 
Volume 1, Issue 1: New Directions in Media Research 2015

Bentley, O. (2015) interview with author face to face, $20^{\text {th }}$ January.

Born, G. (2004) Uncertain Vision, Birt, Dyke and the reinvention of the BBC. London: Secker \& Warburgh.

Brooks, S. (2006) 'Media groups unite against BBC,' The Guardian, 18 May.

Burrell, I. (2014) 'Exclusive: BBC's 'race problem' gets worse as more ethnic minority staff quit the corporation last year than joined' The Independent, 25 June.

Campion, J, M. (2005) Looks who's talking, Cultural Diversity, Public Service Broadcasting and the National Conversation, Nuffield College Oxford

Cohen, P., \& Gardner, C. (eds.) (1982) It ain't half racist, mum: fighting racism in the media (No. 10) Published by Comedia Pub.

Communications Act (2003), C. 21. London: The Stationary Office. (Part 3, Television \& Radio, Chapter 4, P.236) http://www.legislation.gov.uk/ukpga/2003/21/pdfs/ukpga 20030021 en.pdf (Accessed 8 July 2015)

Cottle, S. (eds.) (2000) Ethnic Minorities and the Media: changing cultural boundaries. Maidenhead: Open University Press.

Curtis, M. (2014) face to face interview with author, $1^{\text {st }}$ December.

Department for Culture, Media and Sport. (2006) A public Service for all: The BBC in the digital age (cm. 6763).

Department for Culture, Media and Sport (2004) Independent Review of the BBC's Digital Radio Services

Debrett, M. (2010) Reinventing public service television for the digital future. Bristol: Intellect.

Dudrah, R. (2005) 'Zee TV', South Asian Popular Culture, 3(1), pp. 33-47.

Fenton, S. (2003) Ethnicity. Cambridge: Polity Press.

Hall, S. and OPEN UNIVERSITY, Culture, Media and Identities Team. (1997) Representation: cultural representations and signifying practices. London: Sage in association with The Open University.

Hall, S. (1990) 'The whites of their eyes: racist ideologies and the media' in Alvarado, M. \& Thompson, O, J. (eds.) The Media Reader. London: The British film institute

Hall, S. et al, (2013) Policing the Crisis, Mugging, the State and Law and order. $35^{\text {th }}$ anniversary edition, London: Macmillan press. Chapter 1

Harb, Z., \& Bessaiso, E. (2006) 'British Arab Muslim Audiences and Television after September 11', Journal of Ethnic and Migration Studies, 32(6), pp. 1063-1076.

Husband, C (2005) 'Minority ethnic media as communities of practice: Professionalism and identity politics in interaction', Journal of Ethnic and Migration Studies. 31(3), pp. 461-479. 
Volume 1, Issue 1: New Directions in Media Research 2015

Husband, C (1994) A Richer Vision: The development of ethnic minority media in Western democracies. UNESCO \& John libbey.

Hartmann, G. P. \& Husband, C. (1974) Racism and the Mass Media: A study of the role of the mass media in the formation of white beliefs and attitudes in Britain. Rowman \& Littlefield.

Kumar, K. (1977) 'Holding the Middle ground: The BBC, the public and the professional broadcaster' in J, Curran. M, Gurevitch. and J, Woolalacott. (eds.) Mass Communication and Society. London: Edward Arnold. pp.234-248

Malik, S. (2013) “'Creative Diversity": The Public Service Broadcasting after multiculturalism', Popular Communication: The International Journal of Media and Culture, 11(3), pp. 227-24.

Malik, S. (2008) 'Keeping it real, the politics of channel 4 Multiculturalism, mainstreaming and mandates', Screen, 49 (3), pp. 343-353.

OFCOM (2014) Public Service Content in a Connected Society: Ofcom's third review of public service broadcasting, consultation paper (15 December)

OFCOM (2008) Ethnic Minorities: At the forefront of digital communications in the UK Media, Guardian Ethnic Media Summit 16 September

Purhoit, K, (2015) face to face interview with the author

Saha, A. (2012) 'Beards, scarves, Halal Meat, Terrorists, Forced marriage: Television industries and the production of race', Media Culture and Society, 34(4), pp. 424-438.

Silverton, K, (2015) face to face interview with author, 23 June.

Times of India, 2009, 'UK Sikhs accuse BBC of racism', 20 August. Available at : http://timesofindia.indiatimes.com/world/uk/UK-Sikhs-accuse-BBC-ofracism/articleshow/4914512.cms (Accessed 5 Jan 16)

Van Dijk, T. (1993) Elite Discourse and Racism. Sage

\section{Biography}

Gurvinder Aujla-Sidhu is a Journalism Senior Lecturer at De Montfort University were she is also currently completing her Phd. Gurvinder's research examines how Public Service Broadcasting engages with minority audiences. This paper highlights some of the early interview findings for the research and briefly summarises the literature review. Prior to working in higher education, Gurvinder spent more than 10 years working as a broadcast journalist working for a number of years as a journalist/producer at the BBC Asian Network. The previous work history prompted the research project. 
Contact author(s):

gaujla-sidhu@dmu.ac.uk

\section{Contact for(e)dialogue}

General inquiries at foredialogue@leicester.ac.uk

Editorial inquiries at foreditorial@leicester.ac.uk 